\title{
NEW BRACHYURAN CRABS FROM THE EARLY CRETACEOUS ROMUALDO FORMATION AND THE TETHYAN MARINE INFLUENCE IN THE ARARIPE BASIN, BRAZIL
}

\author{
Prado, L.A.C. ${ }^{1,}$; Luque, J. ${ }^{2}$; Barreto, A.M.F. ${ }^{1}$ \& Palmer, A.R. ${ }^{2}$ \\ ${ }^{1}$ Universidade Federal de Pernambuco (UFPE), Campus Recife, Laboratório de Paleontologia- PALEOLAB. \\ ${ }^{2}$ University of Alberta, Edmonton, Alberta, Canada. \\ *Corresponding author: prado.lac@gmail.com
}

\begin{abstract}
The Romualdo Formation (Early Cretaceous, Aptian-Albian) of the Araripe Basin in Brazil is known worldwide for the exceptional preservation, abundance, and diversity of fossil vertebrates and invertebrates. As for the decapod crustacean fauna, only one species of true crabs (Brachyura) is known to date: Araripecarcinus ferrerai. Here we present 30 brachyuran crabs specimens collected during several recent paleontological surveys in the municipalities of Araripina and Exu, state of Pernambuco, represented by the dorsal carapaces associated with echinoids and molluscs. The carapaces show no signs of abrasion, corrosion, or preferential position, and they are complete or with fragments slightly displaced, suggesting a short distance transport or remobilization in their own environment (i.e. parautochthonus). Two new genera and species were identified: 14 specimens represent a raninoidan of the family Orithopsidae, and 16 specimens are apparently one of the oldest Eubrachyura or 'higher' true crabs known to date. The presence of similar taxa in northern South America, southern North America and Western Europe during the Early Cretaceous reinforces the hypothesis of a tethyan marine influence in the Araripe Basin.
\end{abstract}

Keywords: Crustacea, Decapoda, Orithopsidae, Eubrachyura, Santana group. 